\title{
A RELAÇÃO ENTRE ORDEM E SISTEMA NO DIREITO E A FORMA NA OBRA DE ARTE: O CONFRONTO COM A MATERIALIDADE DA VIDA NO CONTEXTO DA REALIDADE BRASILEIRA
}

\author{
THE RELATIONSHIP BETWEEN ORDER AND SYSTEM IN LAW AND THE \\ FORM IN THE WORK OF ART: THE CONFRONTATION WITH THE \\ MATERIALITY OF LIFE IN THE CONTEXT OF THE BRAZILIAN REALITY
}

\author{
${ }^{1}$ Francisco Cardozo Oliveira \\ ${ }^{2}$ Nancy Mahra de Medeiros Nicolas Oliveira
}

\section{RESUMO}

O artigo analisa a relação entre a ordenação do direito e a forma na obra de arte, na modernidade e na pós-modernidade, e no contexto da realidade brasileira. Busca-se estabelecer a capacidade da ordenação do direito de arbitrar conflitos na sociedade pósmoderna, que abdicou de propósitos inclusivos, confrontada com as possibilidades criativas da forma da obra de arte no contexto da sociedade de consumo. O objetivo é identificar os fundamentos que unem a ordenação do direito e a forma na obra de arte e sua relação com os desdobramentos materiais da vida social.

Palavras-chave: Direito; Ordenamento; Forma; Arte; Sociedade.

\begin{abstract}
The article analyzes the relationship between the order of law and order in the work of art in modernity and post modernity and in the context of Brazilian reality. Seeks to establish the capacity of order the law to arbitrate conflicts in the post- modern society, who abdicated inclusive purposes, faced with the creative possibilities of the art form of work in the context of the consumer society. The goal is to identify the foundations that unite the ordain of law and order in the work of art and its relationship to the material developments of social life.
\end{abstract}

Keywords: Law; Order; Form; Art; Society.

\footnotetext{
${ }^{1}$ Mestre e doutor pela Universidade Federal do Paraná (UFPR), Curitiba, Paraná, Brasil. Professor do Mestrado e da Graduação em direito no Centro Universitário Curitiba (UNICURITIBA), Curitiba, Paraná, Brasil. e Juiz de Direito pelo Tribunal de Justiça do Paraná (TJPR), Paraná, Brasil. Email: xikocardozo@msn.com

${ }^{2}$ Mestre em direito pela Pontifícia Universidade Católica do Paraná (PUCPR), Curitiba, Paraná, Brasil. Juiza do Trabalho

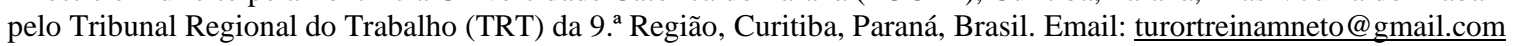




\section{INTRODUÇÃO}

$\mathrm{O}$ artigo trata da relação entre ordem e sistema no direito e forma na obra de arte, ao longo da modernidade e da pós-modernidade, que engloba a realidade brasileira. Enquanto a ordenação do direito buscou afirmar uma racionalidade específica de diferenciação, suficiente para enfrentar o potencial de conflitos da realidade social, sem riscos de contradição e de insegurança, a produção da obra de arte esteve confrontada com a afirmação de uma forma capaz de captar os desdobramentos da vida em sociedade, ou para usar uma premissa de Georges Didi-Huberman, de dar forma a uma desordem (2015). De um lado, a questão entre direito e moral buscou solução no idealismo da positividade da lei ou na abstração dos conceitos, uma maneira de manter a coerência de propósitos de justiça e de igualdade diante de uma realidade de permanência da injustiça e de desigualdades; de outro, a produção da obra de arte se esmerou em perseguir uma forma que se mostrasse efetiva na elaboração daquilo que o artístico tem de valor específico e, desse modo, não se deixasse dissolver no cotidiano e no comum do sentido cristalizado. O problema da análise, portanto, consiste no enfrentamento dos termos dessa relação e do modo como ela repercute efeitos na compreensão da normatividade, e seus desdobramentos materiais na vida social. Elabora-se o confronto entre ordem e sistema no direito e a forma na obra de arte mediante três níveis de análise: o primeiro trata do modo como no direito operou-se a passagem entre a noção de ordem e de sistema; o segundo trata do problema da forma na obra de arte; no final, devem emergir da análise os paradoxos na sistematização do direito e o estreitamento enfrentado na produção da obra de arte, com seus reflexos na construção da socialidade e na vida da pessoa no mundo contemporâneo, em especial na realidade brasileira. O objetivo é o de, a partir da análise proposta, identificar impasses e saídas na operatividade do direito e na produção da arte e o que disso resulta para a evolução social levando em conta também a realidade brasileira. Utiliza-se um método dialético e crítico, em que pressuposto que o método se revela na medida em que se desenvolve a análise. 


\section{A PASSAGEM DA ORDEM AO SISTEMA NO DIREITO: A FUGA DO REAL}

O problema da ordenação do direito comporta duas dimensões imbricadas: uma lógica, que diz respeito ao processo de sistematização, e outra histórica, que pode ser mais facilmente compreendida pela reconstrução do processo de racionalização da vida e que alcança o seu momento específico no desenvolvimento da modernidade. Na perspectiva de uma sociologia da ordenação do direito, Max Weber defende a configuração de uma passagem do direito revelado para o direito positivo, no aspecto formal, e, no material, de um direito tradicional para um direito natural (2004, p. 133-141). Na interpretação do processo de racionalização do direito no pensamento de Max Weber, Carlos Eduardo Sell afirma que ele pode ser compreendido por dois critérios: o da generalização e o da sistematização; enquanto a generalização reduz as razões de decidibilidade a princípios, a racionalização opera a interrelação entre os vários institutos jurídicos, de modo a estabelecer um sistema lógico de regras (2013, p. 102-106). A generalização e a sistematização observam uma dinâmica de estruturação lógica e científica do direito capaz de assimilar os desdobramentos da ação social que se orienta, segundo o próprio Max Weber, pelas ações dos outros e tem uma determinante inerente à evolução social. A generalização e a sistematização do direito, em última instância, estão relacionadas ao modo como a ação social confere sentido à liberdade que, para Max Weber, segundo Karl Loewith, liga a racionalização da vida a uma realidade sóbria e "nãoheróica" do homem e do individualismo característico da modernidade e da sociedade capitalista (1983, p. 145-162).

A ordenação do direito, portanto, não está dissociada do modo como compreendida e organizada a vida em sociedade, de tal forma que, tratar da ordenação do direito exige, ao mesmo tempo, compreender como é organizada a vida em sociedade. A ordenação do direito, porém, não pode ser reduzida a um aspecto antropológico ou sociológico; a ordem no direito também contempla elementos epistemológicos, porque mediante a ordenação normativa também se estrutura a forma de acesso e de instrumentalização do saber jurídico.

Desde o direito romano, com a compilação do Corpus Iuris Civilis de Justiniano, segundo Ovídio A. Baptista da Silva impregnado de valores do cristianismo, a jurisdição perde o poder de império e a caridade passa a servir de correção aos rigores da norma; a ordenação de normas jurídicas insere-se em uma perspectiva de racionalidade que alcança o conhecimento e a prática do direito (1996, p. 91-101). 
A ideia de ordem no pensamento de Santo Tomás de Aquino e de Santo Agostinho é determinante para a sistematização do direito moderno, ainda que esteja voltada para a ordenação do direito medieval. Em Tomás de Aquino, na Suma Teológica, a ideia de ordem assume um caráter realista, na esteira da filosofia aristotélica e da cristianização do direito romano; a ação do homem no mundo ocupa posição em uma ordem divina da vida; a realidade, portanto, é portadora de uma ordem - a ordem do direito natural (Tratado da Justiça, Questão 57); logo, o direito também se insere nessa realidade que observa uma ordem inscrita no mundo por Deus. Contudo, como o homem é feito à semelhança de Deus, a ele cabe atuar no mundo de modo a completar essa ordem primeira, o que ocorreria por meio do direito positivo, e de um critério de adequação, capaz de disciplinar ações e prescrever finalidades. Para Santo Agostinho, no De Ordine, a ordem não se confunde com o conjunto das coisas; antes é a linguagem ou o pensamento que confere ordem ao conjunto ordenado (Corpus scriptorum ecclesiasticorum latinorum). No contraste entre as ideias de Tomás de Aquino e de Santo Agostinho sobre ordem surgem os elementos que estão na base da construção da ordenação do direito na modernidade; de um lado uma ordem social em que se insere a ordenação do direito; de outro, uma ideia de ordenação do direito que ordena a vida social como ideia; ou seja, uma ordenação do direito cujos elementos estão inscritos na vida social e uma ordenação do direito que observa um conceito, ou uma forma que ordena a vida social. O nominalismo de Guilherme de Occam acentua a importância dos elementos conceituais na compreensão e na ordenação do direito, em detrimento da visão realista que inspira o pensamento de Tomás de Aquino.

Inscreve-se na ordenação do direito moderno, dessa forma, uma dicotomia decorrente do confronto entre a ordenação da normatividade do direito e o modo como essa ordenação está relacionada à estrutura da vida social. O jusracionalismo postulou uma ordenação racional do direito de que derivou a codificação, que constitui a forma com que a ordem ganhou materialidade no direito moderno. De outro lado, o positivismo reduziu a normatividade ao imperativo do direito positivo.

Nos termos de uma reconstrução histórica, a distinção entre ser e dever-ser, cujas premissas podem ser localizadas na Metafísica dos Costumes de Kant (2003), pode constituir um eixo para encaminhar os desdobramentos da ordenação do direito na modernidade. A separação entre ser e dever-ser, de acordo com José Lamego, estabeleceu os fundamentos de uma ciência descritiva do direito, como apoio epistemológico para o positivismo conceitual, em que sustentada a possibilidade de uma obrigação jurídica sem comprometimento com a sua realização na realidade (1990, p. 241-247). Nesse sentido, tornou-se possível afirmar uma 
perspectiva normativa do direito, em que a validade das normas pode ser deduzida apenas do sistema de normas, no sentido do proposto por Hans Kelsen, sem necessariamente assumir pautas valorativas (2009). De outro lado, estabeleceu-se uma separação objetiva entre fatos e normas, em que pese a adoção de uma perspectiva interna ao direito. Dissociou-se a normatividade do direito do caráter vinculante da moral; o direito pode ser considerado válido sem a adesão valorativa dos destinatários. Operou-se, portanto, uma separação entre direito e moral; o debate entre Ronald Dworkin e Herbert Hart é representativo dessa separação que permanece controversa até os dias atuais e, em certo sentido, demarca o caráter problemático da ordenação do direito e sua relação com a realidade da vida em sociedade.

\subsection{O dilema da ordenação entre direito e moral: o lugar da realidade}

O debate em torno da separação entre direito e moral, que não deixa também de estar relacionado à relação entre ser e dever-ser, exige considerar o alcance da virada linguística e o quanto, a partir dela, se tornou necessário recorrer à filosofia para dar conta dos fundamentos do sistema jurídico na pós-modernidade. Como afirma Ronaldo Porto Macedo Junior, na segunda metade do Século XX, o debate metodológico no direito incorpora elementos da filosofia analítica e da filosofia da linguagem (2014, p. 52-65). E o problema metodológico envolve a questão da ordenação do direito que precisa considerar fatos, normas e valores e que, portanto, confronta a ordem das regras positivas e a ordem da realidade social. Grande parte dessa questão está relacionada ao debate sobre a relação entre direito e moral no pensamento de Herbert Hart e Ronald Doworkin.

É necessário verificar então até que ponto a contraposição entre o pensamento de Herbert Hart e Ronald Dworkin evidencia uma construção formal dos fundamentos da ordem jurídica. Essa perspectiva se torna relevante no contexto da realidade brasileira em que, conforme afirma Sérgio Buarque de Holanda, a cultura é a do vício do bacharelismo: "um amor pronunciado pelas formas fixas e pelas leis genéricas que circunscrevem a realidade complexa e difícil dentro do âmbito dos nossos desejos" (1995, p. 157) e que, segundo ele, explica o sucesso do positivismo no Brasil. Curiosamente, como assinala o próprio Sérgio Buarque de Holanda, os positivistas no Brasil não eram positivistas no sentido do preconizado por Augusto Comte no discurso sobre o espírito positivo; eles viveram narcotizados pela crença em princípios e o comportamento em relação a eles, que lhes permitia afirmar que 
tinham nojo da política, ou seja, de dar conta da positividade do real e de assumir formas de evasão da realidade (1995, p.159).

É importante neste momento fixar o que se entende por realidade. Na compreensão do que seja a realidade pode ser utilizada a ideia de Gyorgy Lukács; ele afirma que a realidade trata do curso da vida e das inter-relações cotidianas de cada ser humano (2010, p. 68-69). Tomada essa perspectiva, o que constitui a realidade diz respeito à materialidade das relações sociais que resulta do encadeamento das ações humanas no mundo. A necessidade de buscar na filosofia uma concepção de realidade se justifica quando colocado em questão o problema do ser. Para uma concepção estritamente jurídico-formalista o ser, que se contrapõe ao deverser, se refere aos fatos objetivos derivados da ação humana na vida em sociedade. Nesse sentido, o ser é o elemento da realidade que, por meio do silogismo, permite a incidência da norma (dever-ser). Contudo, vista em uma perspectiva de caráter existencial, apoiada no pensamento de Heidegger, por exemplo, o Ser comporta uma divisão fundamental: o da abertura que permite que as coisas surjam no mundo e o da realidade das coisas existentes no mundo (2014). A ideia de Ser, desse modo, pode envolver a própria ação do homem no mundo como abertura e a existência das coisas propriamente ditas; assim, existe uma normatividade material, desdobrada na realidade, que se mostra na esfera do ser cuja complexidade cobra sentido em termos de ordenação e de sistematização.

A concepção dos princípios procurou responder a essa necessidade de conexão ordenadora entre a realidade do ser e a do dever-ser. Desde uma perspectiva principialista, Ronald Dworkin defende a premissa de que o sistema jurídico fornece uma resposta correta que precisa ser encontrada pelo juiz, ainda que, em alguns casos, ele não possa alcançá-la (2011). A ideia é a de que os direitos já estão inscritos no ordenamento jurídico. Herbert Hart, por outro lado, pressupõe que, na medida em que existente uma pluralidade de princípios, não pode ser demonstrado que certa decisão é a única correta (1986). Logo, evidencia-se que, na perspectiva do pensamento de Herbert Hart, poderia ser alcançada maior aderência a uma premissa de justiça material, na perspectiva da realidade. Herbert Hart poderia abrir caminho para uma visão intersubjetiva na relação entre direito e moral, na direção do que afirma Jürgen Habermas que sustenta que, na ordenação formal do direito, existe um conteúdo moral implícito, de modo que a sistematização do direito exige uma democracia realizada (1992).

A controvérsia entre direito e moral, que envolve a dinâmica da relação entre ser e dever-ser, mantém o problema da ordenação do direito enredado em fundamentos idealistas, sem compromisso preciso com as mudanças sociais necessárias para reduzir a injustiça, em especial em sociedade desiguais, como ocorre no Brasil. 


\subsection{A redução da complexidade da vida e o direito como sistema}

A ordenação do direito como sistema de normas se mostrou limitada, mesmo apoiada em uma perspectiva principialista, diante dos desdobramentos tecnológicos e econômicos da sociedade pós-moderna. Tornou-se necessário considerar os efeitos da complexidade da vida social na compreensão da normatividade jurídica. Passou-se de uma concepção de sistema jurídico ou de ordenamento jurídico para a de direito como sistema; se de um lado a questão metodológica exigiu fundamentos filosóficos no direito, agora a exigência de fundamentos sociológicos se impõe por meio do acolhimento dos pressupostos da teoria dos sistemas.

O funcionalismo sistêmico ganhou novo impulso a partir das propostas formuladas por Talcott Parsons, em meados do Século XX (1974). Mas é Niklas Luhmann quem vai desenvolver os fundamentos da teoria dos sistemas para dar conta da complexidade da sociedade pós-moderna. O objetivo da teoria dos sistemas, aplicada ao direito, é identificar uma forma de reduzir a complexidade da realidade, mediante um processo de diferenciação que permita estabelecer a operatividade do ordenamento jurídico. Segundo Niklas Luhmann, a estabilização do sistema jurídico pode ser alcançada mediante a aplicação de uma lógica de input/output, que possa orientar a tomada de decisões. O fechamento operativo do sistema é determinado pela autopoiesis que, a partir do processo de diferenciação, permite o funcionamento das próprias operações; o sistema, portanto, opera por meio de um processo de autorreferencialidade. A relação entre sistema e meio, de acordo com Niklas Luhmann, se apoia na concepção de acoplamento estrutural em que, de um lado, o sistema desenvolve um campo de indiferença com o meio e, de outro, canaliza para o sistema um determinado encadeamento de causalidade (2010, p. 131-132). A ideia de acoplamento estrutural permite ao sistema elaborar a filtragem do encadeamento de causas e efeitos que possam influenciar sua operatividade.

Marcelo Neves elabora a compreensão da premissa de acoplamento estrutural para o direito, tomando a perspectiva do ordenamento jurídico brasileiro, que serve para evidenciar a operatividade da teoria sistêmica. Ele retoma o conceito de Niklas Luhmann de acoplamento estrutural (strukturelle Kopplung) para enfatizar que a Constituição funciona como mecanismo de interpenetração permanente entre dois sistemas sociais autônomos, a política e o direito. Cabe à Constituição, nessa perspectiva, filtrar as influências recíprocas entre 
política e direito. A operatividade propiciada pelo acoplamento estrutural, na visão de Marcelo Neves, representaria um antídoto ao perigo da "politização" e a sobreposição ao código lícito/ilícito que garante o fechamento do sistema do direito (2006, p. 95-106). O modelo de acoplamento estrutural, portanto, busca estabilizar formas de influências recíprocas entre o sistema jurídico e a sociedade. A diferenciação que a ideia de acoplamento estrutural proporciona manteria a salvo a operatividade do sistema jurídico. Contudo, ela só produz efeitos na medida em que a organização da vida social tenha atingido um estágio de consolidação do processo de diferenciação sistêmica, capaz de efetivar o Estado Democrático de Direito. Sobre essa restrição operativa, Marcelo Neves adverte que, tomada a realidade brasileira, no contexto da modernidade periférica, a exclusão de direitos e a falta de cidadania como mecanismo de integração jurídico-política de grande parte da população atua para produzir uma desconstitucionalização fática no processo de concretização de direitos, que inviabiliza as promessas do Estado Democrático de Direito (2006, p. 244-258). A análise de Marcelo Neves evidencia os limites da teoria sistêmica na compreensão do direito em sociedades assimétricas e desiguais como a brasileira, que ingressaram na pós-modernidade, sem alcançar os níveis de evolução social das sociedades do centro da economia capitalista.

Para Pietro Barcellona, a teoria sistêmica de Niklas Luhmann aprofunda a estratégia normativista de Hans Kelsen, na medida em que, na contraposição entre a esfera normativa e a complexidade da vida social, introduz o sistema, que regula um modo de relação condicional entre a forma da ordem jurídica e os conteúdos materiais dos fatos da vida; ao mesmo tempo em que o sistema atua para reduzir a complexidade da vida social, reproduz essa mesma complexidade no seu interior mediante processos de diferenciação funcional (2003, p. 71-119). Assim, a ordem do direito como sistema reproduz, em escala mais abstrata e artificial, o refúgio da normatividade nos limites da lei positiva e no pretenso caráter objetivo dos conceitos jurídicos.

No contexto da pós-modernidade e da intensificação da forma rentista da economia capitalista, pensar o direito como sistema implica adotar um eixo em que o problema da normatividade jurídica continua apoiado em uma concepção formal da norma e da teoria. De modo a manter um mínimo de integridade operativa, o sistema jurídico cria um paradoxo: precisa enfrentar demandas sociais por novos direitos e demandas econômicas por restrições de direitos existentes. Niklas Luhmann diria que é exatamente essa a função da teoria sistêmica: enfrentar paradoxos; o problema, contudo, surge quando os paradoxos inviabilizam a evolução social e desmascaram a precária ordenação formal do direito, que se revela impotente diante da complexidade da vida em sociedade. 


\section{A FORMA NA OBRA DE ARTE: A ARTE IMITA A VIDA}

A forma na obra de arte pode ser analisada em diferentes perspectivas. O problema da forma está relacionado ao que é específico e sublime na obra de arte, que lhe garante uma diferenciação de sentido que se mantém no horizonte histórico, ao mesmo tempo em que incorpora conteúdos materiais das relações de vida em sociedade. A forma envolve uma relação entre a realidade e a obra de arte. Como diz Theodor W. Adorno, os problemas imanentes da forma da obra de arte são os antagonismos não resolvidos da realidade; a obra de arte não simula a literalidade do que exprime; o que é real nela é a resposta à interrogação que vem da vida social (2012, p. 18). Pode-se estabelecer uma linha de compreensão da forma na obra de arte, que tenha como relevante alguns aspectos da relação que ela tem com a realidade social. Nesse sentido, é possível fixar três momentos dessa relação entre a forma da obra de arte e o fluxo do tempo histórico e social, tomados como representativos para uma análise comparativa com o problema da ordenação do direito. O primeiro deles pode ser identificado na passagem do medievo para a modernidade, e as rupturas que se tornaram necessárias para a transição e consolidação de uma nova ordem de valores e seus reflexos na forma da obra de arte; o segundo momento pode ser situado no início do Século XX em torno de uma fenomenologia da busca da forma que está implicada, por exemplo, nas técnicas do cubismo, e mesmo do surrealismo. O último momento, ligado ao segundo, trata das possibilidades da forma da obra de arte na era pós-industrial, saturada de imagens pela tecnologia digital.

\subsection{A produção da obra de arte e a negação do trabalho}

O modo como a arte exprime o trabalho revela um dos principais antagonismos não resolvidos na realidade social que repercute na forma da obra de arte. Sérgio Ferro elabora 
um painel do modo como a fatura artística, na transição do medievo para a modernidade, apoiou-se em uma técnica de modo a, em determinados momentos, fazer desaparecer os vestígios do trabalho, para diferenciar-se do artesão, e, em outros momentos, mostrar uma particularidade da produção do artístico; o liso da superfície que Leonardo da Vinci elabora esconde o trabalho e tenta superar o virtuosismo do artesão; Michelangelo substitui o liso pela singularidade, a sprezzatura, como se o fazer artístico não exigisse esforço; por outro lado, a prática de Michelangelo, de deixar obras inacabadas, é reveladora de uma técnica de non finito, que Sérgio Ferro associa a uma liberdade possível em face da crescente subordinação do trabalho, no contexto de transição sob o domínio do capital; na obra de Tintoretto emerge a aceleração e a inquietude, a pressa de quem precisa produzir para obter o sustento; Velázquez condensa as contradições do Renascimento italiano buscando equilibrar distanciamento e proximidade do trabalho artesanal (2015); em Velázquez, segundo Sérgio Ferro, "A pincelada vaidosa, que se deleita no inacabado e entrega-se ao desleixo aristocrático para afastar-se da monotonia artesanal, retorna sobre si apurando seu virtuosismo calado - tudo num só toque." (2015, p. 199).

O jogo de mostrar e ocultar o fazer na obra de arte revela a relação que se estabelece entre a forma e a realidade social, em que o trabalho livre cede lugar ao trabalho subordinado, característico da economia capitalista. A forma que a produção artística assume no Renascimento italiano confronta as contradições do momento em que se opera a mutação no trabalho e seus desdobramentos na construção da socialidade. Deprecia-se o trabalho artesanal, a liberdade da manufatura dos ofícios, ao mesmo tempo em que ganha sentido o trabalho subordinado, que exprime uma forma de rebaixamento social.

Analisando o contexto do fim da Idade Média, Erich Auerbach ressalta o desvalor do trabalho para os burgueses que, no intuito de manter suas riquezas acumuladas, procuravam cargos e funções na burocracia do Estado e fugiam de atividades de comércio. De acordo com Erich Auerbach "Criaram-se cargos que exigiam pouca ou nenhuma atividade ao lado de cargos que constituíam uma profissão real, havia nomeações puramente decorativas que deixavam seus ocupantes em completo ócio - como já era o caso de muitas posições na Igreja e na corte." (2007, p. 259). Havia, portanto, uma hostilidade e um desprezo pelas ocupações profissionais, o que evidencia que o trabalho como expressão da pessoa perde seu sentido na medida em que passa a ser assalariado e, consequentemente, subordinado.

A forma da obra de arte procura assimilar o antagonismo que enreda o trabalho: ao mesmo tempo em que o trabalho é rebaixado pela subordinação, ele se torna indispensável para a acumulação de capital; apesar do desprestígio da pessoa que vive do trabalho, é 
necessário que haja trabalho para assegurar o sustento pessoal. O antagonismo surge na forma da obra de arte nos desdobramentos do processo de produção e do fazer; contudo, como não pode ser suprimido de todo, o fazer retorna como resistência ou bloqueio porque, como diz Sérgio Ferro, não é possível suprimir o trabalho livre na arte; na resistência, o retorno se revela crítico; no bloqueio, se consuma o sofrimento e a fuga da realidade.

\section{2 $\mathrm{O}$ trabalho artístico diante da redução da vida à forma mercadoria}

No contexto atual de pós-industrialização, o que deve emergir na obra de arte, segundo Richard Serra, são exatamente as pegadas da fenomenologia do fazer, da produção e do construído; diz ele que é necessário compreender que, na escultura, a matéria impõe sua forma à forma. Daí a perspectiva que Richard Serra atribui ao minimalismo de fazer com que o objeto artístico incorpore a experiência e as contingências do mundo real (2014). É exatamente neste ponto de incorporação do mundo real e de construção do objeto artístico que pode ser analisado o problema da forma da obra de arte que se colocou para o cubismo e, de certo modo, para o surrealismo.

O problema da forma no cubismo, segundo Rosalind Krauss, confronta Picasso com o dilema da produção do artístico em face da redução do espaço de invenção provocado, segundo ela, pelo esvaziamento do signo na modernidade e a dificuldade de estabelecer o que é verdadeiro ou falso, de que resulta o pastiche (2006). O pastiche constitui então a estratégia para enfrentar os limites da criação nos moldes do proposto pelo modernismo. Sobre essa questão Teodor W. Adorno, quando trata da música, no contraste entre Schonberg e Stravinski afirma que, na música deste último, operou-se uma regressão, na medida em que, na busca por um estado anterior, ele substituiu o progresso pela repetição. O que prometia ser inovador se transforma em imitação. Mas esse impulso restaurador, segundo Adorno, pode ser explicado por uma relação com o estágio da realidade social, em termos antropológicos; diz ele que Stravinski, à semelhança de Picasso, com o neoclassicismo a partir de 1920, respondeu ao impulso social de adaptação, em que a organização social exigia a sedução por um passado primitivo, que carrega o horror pelo futuro do homem; a forma estética acalma a angústia e reforça a sedução (1974, p. 109-165). Adorno sublinha que a música, desde que existe, tem sido o protesto contra o mito e o destino perene, contra a morte; a música não se desprende de sua essência antimitológica mesmo quando faz do mito seu próprio tema; a 
liberdade é imanentemente necessária à música e constitui sua essência dialética. Stravinski negou o dever musical da liberdade, segundo Adorno, sob o desespero que forçaria a própria música a emudecer (2006, p. 391-417). Ao mesmo tempo em que a música de Stravinski avança em razão do contexto histórico da forma, ela está montada a partir de repetições e, nesse sentido, incorpora o retrocesso. Adorno lembra Ernst Bloch para quem o eterno retorno é uma eternidade mal imitada a partir de repetições infinitas (2006, p. 391-417).

O que determina as limitações na obra de Stravinski também está presente na arte de Picasso na mesma época. Ainda que do ponto de vista do contexto histórico a forma da arte esteja aberta às possibilidades de inovação técnica, opera-se o retrocesso que se materializa na imitação paralisante como se reduzidas as alternativas.

Embora reconheça que o cubismo continua a ser obra de Picasso, Rosalind Krauss afirma que se instalou na arte dele, no começo do Século XX, o que ela denomina de formação reativa, em uma luta contra os atrativos da decoração kitsch, o mecânico e a automação tecnológica; Picasso apela para o virtuosismo como forma de defesa da arte - e nisso imita o Renascimento italiano na luta contra o artesanal - ao mesmo tempo em que faz de sua vida o paralelo da invenção artística; nesse sentido a vida imita a arte, e não o contrário. Mas a reação, não impediria Picasso de sucumbir à repetição, à cópia e ao pastiche tentando unir cubismo e classicismo (2006, p. 97-204) Assim, a experiência do cubismo permanece obra de Picasso, mas a busca de solução para a arte, em meio à massificação da forma mercadoria e a produção seriada da tecnologia, desemboca na redução do espaço da criatividade e na reação que conduz à cópia, à imitação e à dissimulação: o pastiche. Em síntese, o que Rosalind Krauss afirma é que a formação reativa inclui uma oposição que, de forma dialética, conduz a afirmação do que é negado: o pastiche como a consciência culpada do modernismo.

Desde Picasso a ampliação do consumo e da tecnologia digital multiplicaram oportunidades para a cópia, a imitação e o pastiche, ou para a repetição compulsiva, o "maravilhoso" que desafia a racionalidade, como aponta Hal Foster, no registro psicanalítico do surrealismo (2008). Cabe a advertência de Boris Groys, no sentido de que o desenvolvimento tecnológico não confirmou a assertiva de Walter Benjamin de uma identidade material entre original e cópia (A obra de arte na era da reprodutibilidade técnica); no mundo digital a distinção entre cópia e original, diz ele, se tornou um ato de fé (2014, p. 191). Assim, no momento em que a forma mercadoria dissemina a produção seriada, a cópia que adquire a especificidade de original, a repetição e a imitação, a forma da obra de arte, de modo a preservar o trabalho artístico, se encontra em uma encruzilhada: sucumbir à série, à 
repetição e à imitação, e com isso fundir-se à realidade mercantilizada da sociedade de consumo, ou retroceder para fixar um passado que nega o futuro.

\section{PARADOXOS NA SISTEMATIZAÇÃO DO DIREITO E NA FORMA DA OBRA DE ARTE: OS REFLEXOS NA REALIDADE BRASILEIRA}

No decorrer da análise, já ficaram evidenciados os paradoxos na ordenação do direito e na forma da obra de arte, considerada a relação com a realidade social e histórica. Enquanto no direito se revela a precariedade da ordenação, incapaz de dar conta da complexidade das exigências de justiça na realidade social pós-moderna, com mais intensidade na situação de desigualdades da sociedade brasileira, na obra de arte a invenção, e consequentemente a forma, encontram-se emparedadas pelos limites de fórmulas de retorno e de repetição e pela assimilação da forma mercadoria.

É preciso verificar como esses paradoxos se desdobram na atualidade quando confrontados, no caso do direito, com a judicialização da vida e o dilema da desordem e da sistematização precária e, no caso da forma da obra de arte, com a forma mercadoria e o consumo, no objetivo de estabelecer uma síntese conclusiva capaz de mostrar o que, de fato, une as duas esferas e aponta para saídas.

\subsection{Judicialização da vida, desordem e sistematização precária do direito}

Se já era difícil sustentar os pressupostos da ordenação formal do direito, mediante uma espécie de fuga da realidade, as dificuldades aumentaram em face do que Tércio Sampaio Ferraz Junior identifica como emergência, na atualidade, de uma espécie de desordem, de abandono do codificado e da lei como elementos determinantes da racionalidade de sistematização e de aplicação do direito. Estreitaram-se os limites para a ordenação do direito.

De acordo com Tércio Sampaio Ferraz Junior, opera-se no direito uma passagem entre a centralidade da lei e a centralidade da jurisdição, entendida como protagonismo dos tribunais e agências administrativas; essa mudança de ênfase, notada especialmente no Brasil, diz ele, reorienta a reflexão jurídica para o momento da aplicação e alimenta uma abertura 
para um constitucionalismo principialista e argumentativo. Os indícios dessa mudança podem ser localizados na transformação da compreensão dos direitos, que passa do material para o virtual (direitos autorais e direitos de propriedade), uma realidade em que a tecnologia criou um mundo sem sujeito e vazio de responsabilidade, que deu ensejo ao que ele denomina de sociedade econômica, com a abolição das linhas divisórias entre política e economia; nesse contexto, diz ele, o problema da governabilidade se reduziu a um poder disciplinar e de gestão da economia. Tércio Sampaio Ferraz Junior também elabora um paralelo entre direito e arte; diz ele que na situação brasileira se consolida um direito-espetáculo estetizado, em que se revela a confusão entre a declaração crescente de direitos humanos e as dificuldades de implementá-los; de outro lado, a arte se desestetiza, porque se transforma em produto de consumo (2014).

A análise de Tércio Sampaio Ferraz Junior é ilustrativa da elisão da realidade pelo direito, provocada pela judicialização da vida. Não é possível compreender o papel do direito na atualidade sem levar em conta os processos de judicialização da vida consistentes, segundo Miguel Kfouri Neto e Francisco Cardozo Oliveira, na mediação, pela forma judiciária, de toda espécie de conflito interpessoal, com seus efeitos em termos de estreitamento da compreensão dos fatos e da realidade pelo espetáculo das imagens e pela superficialidade da expressão de sentimentos (2015, p. 203-232).

$\mathrm{Na}$ medida em que a realidade se dissolve no espetáculo das imagens característico da sociedade pós-moderna, a ordenação do direito se desvencilha do compromisso com os desdobramentos da vida social, mas paga o preço da crise da desordem.

Ricardo Luiz Lorenzetti aponta vários elementos que, na atualidade, contribuem para o que ele denomina de era da desordem no direito; a confusão entre as esferas do direito público e do direito privado, a descodificação do direito civil, o big bang legislativo, o surgimento dos microssistemas (direitos da empresa, direitos de proteção do consumidor, direito ambiental e direito digital) que convergem para a crise do código e da descodificação; segundo ele, evidencia-se o desprestígio da lei, enquanto comando imperativo, e ao mesmo tempo ocorre a desvinculação de parcelas da sociedade de compromissos com o Estado, que buscam suprir suas necessidades com recursos privados (2008, p. 212-242).

A ordenação está inviabilizada em face de uma evolução social em que o direito opera como estratégia manipuladora da prevalência de interesses mercantis em detrimento dos interesses da pessoa. A tensão entre ordenação do direito e a realidade social encontrou o seu limite apaziguador no exato momento em que a evolução social parece ter se desconectado do compromisso com a ampliação de direitos e com a inclusão e permanece restrita a assegurar 
os pressupostos de uma economia de mercado potencializadora de formas de renda e de cosumo, sem trabalho e sem inovação.

\subsection{O confronto da arte com a realidade da forma mercadoria e do consumo}

Enquanto a tensão entre a ordenação do direito e a realidade social adquiriu um novo patamar de certo modo regressivo, a forma da obra de arte continua a enfrentar a necessidade de dar conta dos termos do trabalho artístico em face da esfera de ampliação da forma mercadoria e do consumo. Como lembra Terry Eagleton, a modernidade tardia está tomada por uma sensação de gratuidade, de carência de fundamentação sólida de suas formas de vida. O escandaloso disso, diz ele, é que poderia não ser assim; e isso também vale para a obra de arte em que, segundo ele, deve incorporar em suas formas uma consciência irônica de sua arbitrariedade, de sua natureza sem fundamento, como tentativa mais próxima do que se chama verdade; assim, se a obra de arte, como a ética, deve ter suas próprias leis isso se deve a que só existe areia movediça sob seus pés. O problema da modernidade tardia, segundo Terry Eagleton, não é um destino poderoso, mas o fato de que não existe um destino em absoluto (2011, p. 177-178). A forma da obra de arte na pós-modernidade está confrontada com o vazio e arbitrariedade paradoxal de fundamentos que conduz a um estreitamento das possibilidades de invenção, em confronto com os riscos da mercantilização e seus processos de repetição e cópia.

$\mathrm{O}$ risco da redução da arte à mercadoria se mostra mais ameaçador no momento em que, por exemplo, a pop art eleva o comum a arte, mediante desestabilização de sentidos, e se amplia o mercado de objetos artísticos. A questão, portanto, é como a forma da obra de arte vai exprimir os antagonismos não resolvidos de uma realidade em que opera a carência de fundamentos, saturada pelos processos de mercantilização, ao mesmo tempo em que, como lembra Hal Foster, nos limites de uma crítica proposta pelo surrealismo, o capitalismo tardio parece não ter mais um exterior e nele o real se tornou surreal (2008, p. 327-332).

Ao mesmo tempo em que adverte que uma reconexão da arte com a vida ocorreu na atualidade nos termos da indústria cultural, e não da vanguarda, cujos procedimentos foram assimilados pela cultura do espetáculo, Hal Foster afirma que os artistas promovem deslocamentos sutis, que constituem um modo de manutenção da vanguarda e, consequentemente, da criatividade artística que não chega a apelar para o hermetismo ou para o formalismo (2014, p. 21-49). Resulta necessário, desse modo, identificar esses 
deslocamentos sutis que tornam possível à forma da obra de arte manter-se conectada à realidade pós-moderna e à criatividade.

Uma dessas saídas é apontada pelo próprio Hal Foster para quem o valor transgressor do minimalismo e da pop art está em fazer uso da lógica da diferença e da repetição, típicas da cultura de massa, mas de maneira subversiva; ele lembra Gilles Deleuze que afirmou que quanto mais a vida cotidiana aparece estandardizada, submetida a uma reprodução acelerada de objetos de consumo, mais a arte deve ligar-se a ela e arrancar a pequena diferença, que atua nos níveis de repetição, descobrindo, sob o consumo, as marcas do sofrimento, a reprodução da estética das ilusões e as mistificações que constituem a essência da civilização consumista (2014, p.51-78). Claire Bishop mostra a importância da ideia de antagonismo para uma concepção de estética relacional, que leva em conta o conflito e o encontro com o outro na construção da socialidade democrática (2004). Na mesma direção, Lorenzo Mammi, mais próximo do panorama da realidade sociocultural brasileira, faz o registro das possibilidades da arte no lugar em que uma experiência sensível, um corpo, uma realidade que ainda possa ser encontrada, tendo-se a consciência de que isso, atualmente, só se dá nas margens e nas esgarçaduras; e conclui afirmando que sempre há espaço para operações estéticas, mesmo num mundo cujo significado já parece dado (2012, p. 54-117).

A forma da obra de arte na contemporaneidade não precisa abdicar de sua relação com a materialidade da vida em sociedade; a expansão da forma mercadoria e do consumo não impede que a obra de arte possa fazer aparecer os antagonismos não resolvidos da vida em sociedade. No caso da sociedade brasileira de profundos antagonismos que permanecem sem solução prevalece um registro trágico, que é o de maiores possibilidades para o aparecimento da obra de arte, paradoxalmente bloqueadas pelas assimetrias e desigualdades que limitam a invenção.

\section{CONSIDERAÇÕES FINAIS}

A análise desenvolvida indica um caráter lógico e histórico na ordenação do direito e na forma da obra de arte. Na ordenação do direito, o trânsito entre uma ordenação de base filosófica e outra de base sociológica, manteve-se no limite de uma compreensão idealista do fenômeno jurídico que, na modernidade, preservou uma concepção formal de direitos e titularidades, em face dos conflitos e assimetrias provocados pelos desequilíbrios típicos da 
economia de mercado. Na forma da obra de arte, os impasses na evolução da socialidade, nos termos da proposta do modernismo, implicaram recuos e perda da vitalidade da inovação.

No momento em que a pós-modernidade se afirma crítica e reflexiva da modernidade, e coloca de forma objetiva os seus limites, a ordenação no direito perde sentido porque a sistematização não se revela mais capaz de dar conta das exigências colocadas pela evolução social. O que permanece da relação entre realidade e direito, na atualidade brasileira, são as necessidades de uma tecnologia punitiva e do estado de exceção. $\mathrm{Na}$ arte, a forma permanece confrontada com a realidade e busca fórmulas para responder aos desafios da repetição, da cópia e do falso que se manifesta na sociedade de consumo, embora tenham se estreitados os caminhos para a inovação.

Uma síntese conclusiva, no modelo de um quadro comparativo, visto na perspectiva dos desdobramentos materiais da vida em sociedade, pode ser elaborada tendo-se em conta que, enquanto o direito na pós-modernidade, em especial na sociedade brasileira, parece não ser mais capaz de arbitrar os antagonismos e opera como ritual e jogo, no sentido do formulado por Johan Huizinga para sociedades em decadência (2015), a forma da obra de arte, mesmo nos limites e nos restos de uma socialidade que abdicou da inclusão, ainda encontra espaços de resistência e de abertura para a inovação e para o trabalho artístico, mesmo que seja apenas para o registro trágico dos rastros do direito deixados pela permanência da injustiça.

\section{REFERÊNCIAS}

ADORNO, Theodor W. Teoria estética. Lisboa: Edições 70 Ltda., 2012.

Filosofia da nova música. São Paulo: Editora Perspectiva, 1974.

Escritos musicales I-III - obra completa 16. Madrid: Ediciones Akal, 2006.

AUERBACH, Erich. Ensaios de literatura ocidental - filologia e crítica. 1. a ed., São Paulo: Editora 34 - Duas Cidades, 2007.

BISHOP, Claire. Antagonism and relational aesthetic. October Magazin. n. ${ }^{\circ}$ 110, 2004, p. 51-79.

BARCELONA, Pietro; GIORGI, Raffaele di; NATOLI, Salvatore. Fine della storia e mondo come sistema: tesi sulla post-modernità. Bari: Edizioni Dedalo, 2003.

DIDI-HUBERMAN, Georges. A semelhança informe - ou o gaio saber visual segundo Georges Bataille. Rio de Janeiro: Contraponto Editora, 2015. 
DWORKIN, Ronald. Levando os direitos a sério. São Paulo: Editora Martins Fontes, 2011.

EAGLETON, Terry. Dulce violencia - la idea de lo trágico. Madrid: Editorial Trotta, 2011.

FERRAZ JUNIOR, Tércio Sampaio. O direito, entre o futuro e o passado. São Paulo: Editora Noeses, 2014.

FERRO, Sérgio. Artes plásticas e trabalho livre - de Dürer a Velázquez. 1. a ed. São Paulo: Editora 34, 2015.

FOSTER, Hal. O retorno do real. São Paulo: Cosac Naify, 2014.

Belleza compulsiva. Buenos Aires: Adriana Hidalgo Editora, 2008.

GROYS, Boris. Volverse público - las transformaciones del arte en el ágora contemporânea. Buenos Aires: Caja Negra, 2014.

HABERMAS. Jurgen. Direito e moral. Lisboa: Instituto Piaget, 1992.

HART, Herbert. O conceito de direito. Lisboa: Fundação Calouste Gulbenkian, 1986.

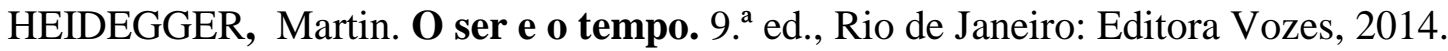

HOLANDA, Sérgio Buarque de. Raízes do Brasil. São Paulo: Cia. das Letras, 1995.

HUIZINGA, Johan. Homo ludens. Madrid: Alianza Editoral, 2015.

KANT, Immanuel. A metafísica dos costumes. São Paulo: Edipro, 2003.

KELSEN, Hans. Teoria pura do direito. 8. a ed. São Paulo: Editora Saraiva, 2009.

KFOURI NETO, Miguel; OLIVEIRA, Francisco Cardozo. O alcance da fundamentação da decisão judicial na relação entre fatos e normas segundo o inciso I do $\S 11^{\circ}$ do artigo 489 do novo Código de Processo Civil. In O dever de fundamentação no novo CPC - análise em torno do artigo 489 (VASCONCELLOS, Fernando Andreoni; ALBERTO, Tiago Gagliano Pinto (Org.). Rio de Janeiro, Lumen Juris Editora, 2015, p. 203-232.

KRAUSS, Rosalind E. Os papéis de Picasso. São Paulo: Editora Iluminuras, 2006.

LAMEGO, José. Hermenêutica e jurisprudência. Lisboa: Editorial Fragmentos, 1990.

LOEWITH, Karl. Racionalização e liberdade: o sentido da ação social. In FORACHI, Marialice Mencarini; MARTINS, José de Souza. Sociologia e sociedade - leituras de introdução à sociologia. Rio de Janeiro: LTC Editora, 1983.

LORENZETTI, Ricardo Luiz. A era da desordem e o fenômeno da descodificação. Revista de direitos do consumidor. São Paulo: Editora Revista dos Tribunais, vol. 68, p. 212-242, outubro-dezembro de 2008.

LUKÁCS, Gyorgy. Prolegômenos para uma ontologia do ser social. São Paulo: Boitempo Editoral, 2010. 
LUHMANN, Niklas. Introdução à teoria dos sistemas. 2. ${ }^{\mathrm{a}}$ ed., Petrópolis: Editora Vozes, 2010 .

MACEDO JUNIOR, Ronaldo Porto. Do xadrez à cortesia - Dworkin e a teoria do direito contemporânea. 1. a ed, 2. ${ }^{a}$ tiragem, São Paulo: Editora Saraiva, 2014.

MAMMI, Lorenzo. O que resta - arte e crítica de arte. São Paulo: Cia das Letras, 2012.

NEVES, Marcelo. Entre Têmis e Leviatã: uma relação difícil. São Paulo: Editora Martins Fontes, 2006.

PARSONS. Talcott. O sistema das sociedades modernas. São Paulo: Editora Pioneira, 1974.

SELL, Carlos Eduardo. Max Weber e a racionalização da vida. Petrópolis: Editora Vozes, 2013.

SERRA, Richard. Richard Serra - escritos e entrevistas 1967-2013. São Paulo: Instituto Moreira Salles, 2014.

SILVA, Ovídio A. Baptista da. Jurisdição e execução - na tradição romano-canônica. São Paulo: Editora Revista dos Tribunais, 1996.

WEBER, Max. Economia e sociedade - fundamentos da sociologia compreensiva. São Paulo: Editora UNB - Imprensa Oficial do Estado de São Paulo, vol 2. 2004. 